\title{
Commentary: Routine lower extremity venous thromboembolism screening following lung transplantation: Seek and ye shall find
}

\author{
P. Michael McFadden, MD, and William Oslund, MD
}

\footnotetext{
From the Division of Thoracic Surgery, Department of Surgery, Keck School of Medicine, The University of Southern California, Los Angeles, Calif.

Disclosures: Authors have nothing to disclose with regard to commercial support.

Received for publication Sept 16, 2019; revisions received Sept 16, 2019; accepted for publication Sept 17, 2019; available ahead of print Oct 28, 2019.

Address for reprints: P. Michael McFadden, MD, Division of Thoracic Surgery, Department of Surgery, Keck School of Medicine, 1520 San Pablo St, Suite 4300, Los Angeles, CA 90033-5330 (E-mail: michael. mcfadden@med.usc.edu).

J Thorac Cardiovasc Surg 2020;159:1152-3

$0022-5223 / \$ 36.00$

Copyright (c) 2019 by The American Association for Thoracic Surgery

https://doi.org/10.1016/j.jtcvs.2019.09.105
}

In this issue of the Journal, Jorge and colleagues ${ }^{1}$ describe a study of 1141 patients at the University of Pittsburgh who underwent routine deep vein thrombosis (DVT) screening following lung transplantation at their institution between January 1, 2005, and December 31, 2014. They describe the incidence and predisposing risks for DVT in these patients. Patients were separated into 2 cohorts, those who were not routinely screened for DVT and those who were screened after lung transplantation when a routine DVT screening protocol was initiated in 2008. Strengths of this study are in its power at 1141 lung transplants and its origin from a reputable, high-volume lung transplant research center. Its weakness relates to a single-institution, retrospective study.

DVT rates before and after routine screening were $8.8 \%$ (36 DVT of 412 transplants) and 17.3\% (126 of 729 transplants), respectively. Although these rates were significantly different $(P<.01)$, the observed DVT incidence per year was not significantly different across the 6 years of universal routine DVT screening. Screening was conducted on days 0 and 14 , a postoperative period when DVT commonly occurs. Patients were followed for 90 postoperative days. When DVT was detected, the patient received standard anticoagulation or an inferior vena cava filter, if anticoagulation was not tolerated. There were no observed DVT differences at day 0 and 14 in the era before routine screening protocols; incidences were $3.8 \%$ and $3.8 \%$, respectively. The cohort after establishment of DVT screening protocol at similar points were $8.7 \%$ and $3.7 \%$, respectively. As a point of reference, the risk of DVT in other major thoracic, vascular, and cardiac procedures is generally as follows: cardiac surgery $2 \%$ to $5 \%$, heart transplantation $14 \%$, lung transplantation $8 \%$ to $27 \%$, vascular $0.99 \%$, and pneumonectomy $3.6 \%$ to $8.9 \% .^{2-5}$

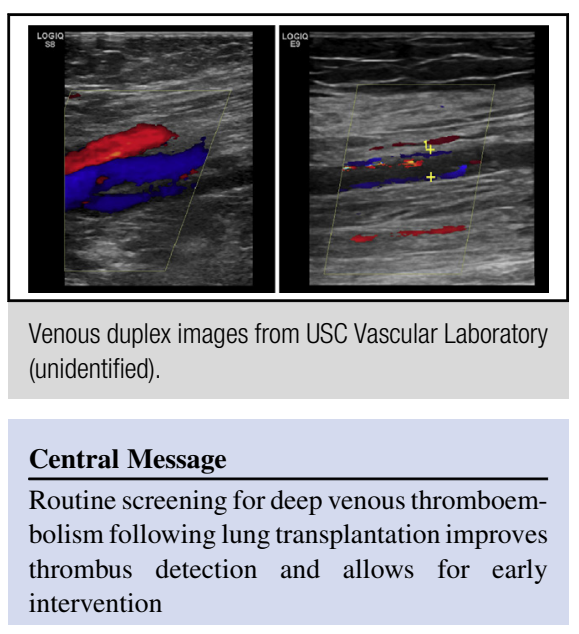

See Article page 1142.
Standard risks for DVT in lung transplantation include advanced age, obesity, diabetes mellitus, pneumonia, prothrombotic state, immobility, cardiopulmonary bypass, and immunotherapy (eg, sirolimus, everolimus). ${ }^{5}$ A surprising observation from this study was that patients who quit smoking versus those that were never smokers developed less DVT. The conclusions of this study were that the rate of DVT diagnosis significantly increased with adoption of a routine screening protocol. In addition, hypercholesterolemia and prolonged length of stay predisposed to the development of DVT in patients undergoing lung transplant.

Advances in medicine are made with determination, dedication, and perseverance but also with observation and sometimes even serendipity. Our impression is that DVT following lung transplantation is far more prevalent than what has been reported. The paper by Jorge and colleagues ${ }^{1}$ validates our concerns and provides impetus for routine screening and early intervention for DVT after lung transplantation.

\section{References}

1. Jorge A, Sanchez PG, Awori Hayanga JW, Pilewski JM, Morrell M, Tuft M, et al. Routine deep vein thrombosis screening after lung transplantation: incidence and risk factors. J Thorac Cardiovasc Surg. 2020;159:1142-50. 
2. Aziz F, Patel M, Ortenzi G, Reed AB. Incidence of postoperative deep venous thrombosis is higher among cardiac and vascular surgery patients as compared with general surgery patients. Ann Vasc Surg. 2015;29:661-9.

3. Mason DP, Quader MA, Blackstone EH, Rajeswaran J, DeCamp MM, Murthy SC, et al. Thromboembolism after pneumonectomy for malignancy: an independent marker of poor outcome. J Thorac Cardiovasc Surg. 2006;131:711-8.
4. Raja S, Idrees JJ, Blackstone EH, He J, Badjatiya A, Mazzone P, et al. Routine venous thromboembolism screening after pneumonectomy: the more you look, the more you see. J Thorac Cardiovasc Surg. 2016;152:524-32.

5. Yegen HA, Lederer DJ, Barr RG, Wilt JS, Fang Y, Bagiella E, et al. Risk factors for venous thromboembolism after lung transplantation. Chest. 2007;132: 547-53. 